\title{
Bat-winged dinosaur discovery poses flight puzzle
}

Tiny creature has forelimb bones thought to support aerofoil membranes.

\section{Sid Perkins}

29 April 2015

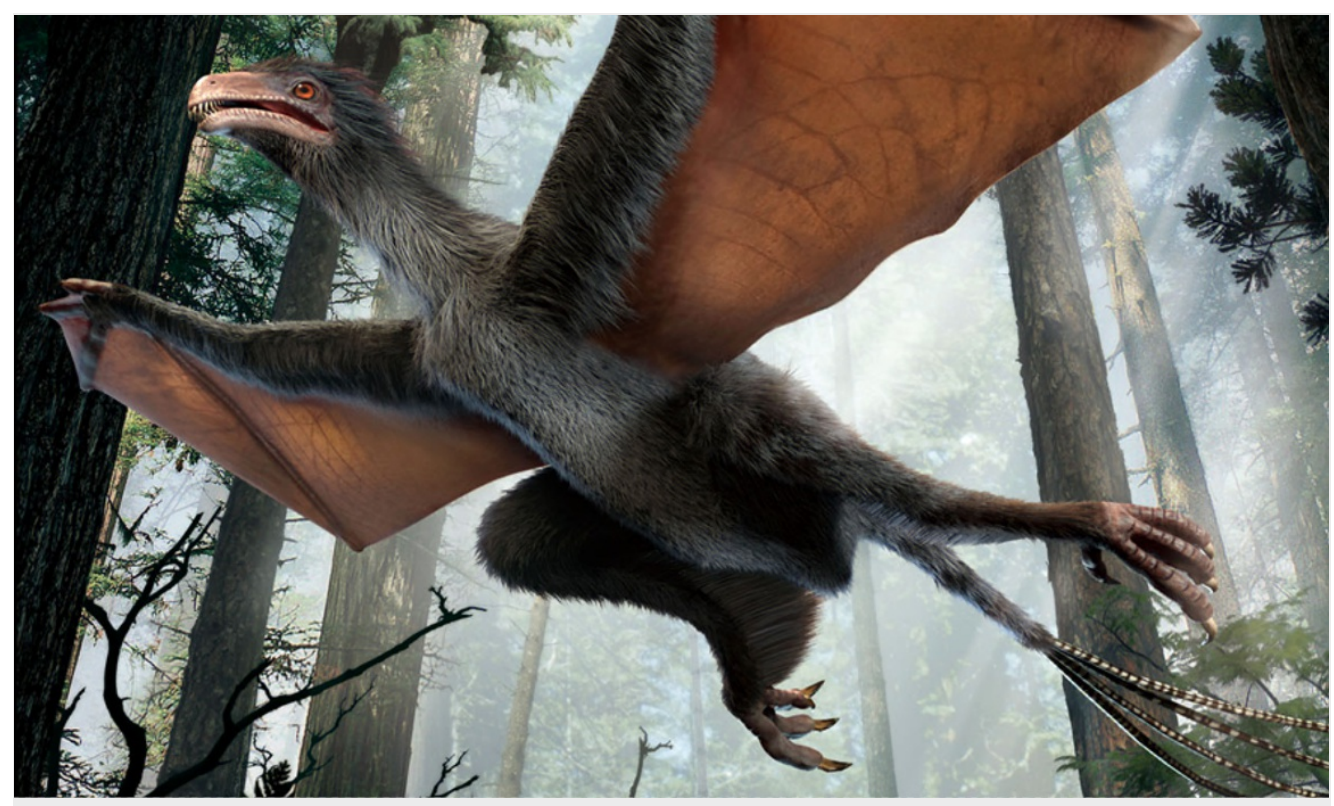

Dinostar Co. Ltd

An artist's impression of the bat-like dinosaur Yi qi.

A small, feathered dinosaur that probably sported bat-like wing membranes might have been able to glide or fly short distances. The fossilized remains of the creature, unearthed in eastern China and described today in Nature ${ }^{1}$, have a 13-centimetre-long, rod-like bone that extends from each wrist, which might have helped to support or position wing membranes; small patches of membranous tissue also cling around the bones. It is the first time such a bone structure has been seen in dinosaurs.

\section{Nature podcast}

Nature reporter Kerri Smith talks to palaeontologist Xing $\mathrm{Xu}$ and editor Henry Gee about the tiny dinosaur $Y_{i}$ qi.

You may need a more recent browser or to install the latest version of the Adobe Flash Plugin.

Go to full podcast
It is difficult to ascertain how much area the dinosaur's wing membranes covered, says Xing $\mathrm{Xu}$, a palaeontologist at the Institute of Vertebrate Paleontology and Paleoanthropology in Beijing and lead author of the paper. The newly discovered species, which lived approximately 160 million years ago, has been dubbed Yi qi, which in Mandarin means "strange wing". $\mathrm{Xu}$ and his colleagues estimate that the creature had a 60-centimetre wingspan and weighed about 380 grams - roughly the size of a magpie but slightly heftier. 


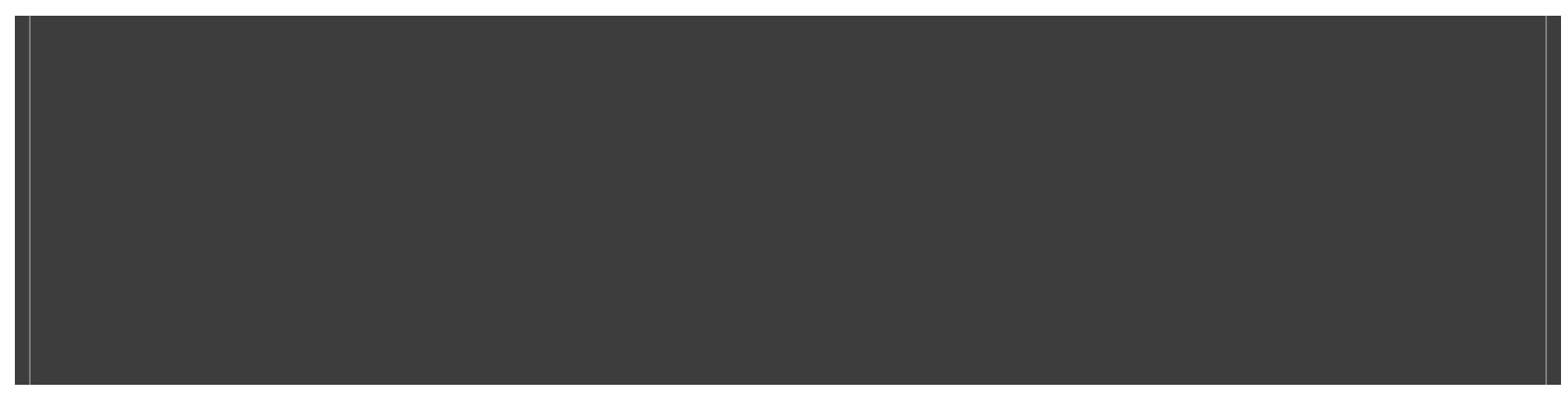

"This is one of the strangest animals that l've seen in the fossil record in years," says Thomas Holtz Jr, a vertebrate palaeontologist at the University of Maryland in College Park. "It's raising a lot more puzzles than it's solving."

\section{Bone to pick}

Xu says that it is not clear whether the rod-like bone extending from Yi qi's wrist remained in one position or could somehow be moved to control the membrane. And on the basis of the one specimen his team has unearthed, he notes that it is difficult to tell whether the creature glided, flapped its wings or alternated between the two, as do some modern-day bats and many birds, including swifts, woodpeckers and finches.

If Yi qi did take to the air, it may have spent most of its time gliding, not flapping its wings, the team suggests. The bone in the wing membrane might have rendered flapping unwieldy, and features on the forelimb bones suggest that the dinosaur's flight muscles may have been relatively small and weak. (The creature's feathers would not have helped it to fly: they are more like stiff, frayed bristles than the aerodynamic structures that today's birds have).

And if its wing membranes were used for flight, the dinosaur's aerial abilities would have evolved separately from those of pterosaurs, a group of ancient flying reptiles that sported wing membranes rather than feathers, says Holtz.

But the dinosaur's membranes might instead have been display devices, says Holtz — used during courtship rituals or to help distinguish themselves from other species. "The temptation to associate these membranes with flight may be misleading," he says.

After all, evolution might have played a similar trick before: many palaeontologists have proposed that feathers first evolved so that dinosaurs could better retain body heat or communicate with potential mates, and that only later were feathers co-opted for the purposes of flight.

Nature I doi:10.1038/nature.2015.17434

\section{References}

1. Xu, X et al. Nature http://dx.doi.org/10.1038/nature14423 (2015). 